\title{
ANALISIS DEBU RESPIRABLE TERHADAP MASYARAKAT DI KAWASAN PERUMAHAN SEKITAR LOKASI PABRIK PT. SEMEN PADANG
}

\author{
Vera Surtia Bachtiar dan Puspa Safitri Sanggar Rani \\ Jurusan Teknik Lingkungan, Fakultas Teknik, Universitas Andalas \\ Kampus Limau Manis, UNAND Padang 25163, Indonesia \\ Email : vera_sb@ft.unand.ac.id
}

\begin{abstract}
ABSTRAK
Penelitian ini bermaksud untuk menganalisis kualitas udara dan dampak negatif yang dirasakan masyarakat dari debu yang berasal dari aktivitas pabrik di kawasan perumahan sekitar lokasi pabrik PT. Semen Padang. Pengukuran kualitas udara dilakukan di 3 kawasan perumahan yaitu komplek perumahan RW. 1 RT. 3 Kelurahan Batu Gadang, Perumnas Indarung RW. VII, dan Perumahan UNAND Blok D Gadut dengan menggunakan alat Personal Dust Sampler. Diperoleh hasil konsentrasi debu respirable pada komplek perumahan RT.3 RW.I Kelurahan Batu Gadang sebesar 0,33 mg/m $\mathrm{m}^{3}$, pada Perumnas Indarung RW.VII sebesar 0,55 mg/ $\mathrm{m}^{3}$ serta pada Perumahan UNAND Blok D Gadut sebesar 0,44 $\mathrm{mg} / \mathrm{m}^{3}$. Konsentrasi debu respirable pada ketiga lokasi masih berada di bawah ambang batas baku mutu udara di lingkungan, $3 \mathrm{mg} / \mathrm{m}^{3}$. Berdasarkan kuesioner dan data puskesmas terdekat dengan menggunakan analisis univariat, dampak negatif yang dirasakan masyarakat adalah dampak terhadap kesehatan berupa penyakit iritasi mata dan dampak terhadap lingkungan khususnya pada kondisi material yang dimiliki masyarakat.
\end{abstract}

Kata kunci: kualitas udara, dampak negatif, kawasan perumahan, debu respirable, PT. Semen Padang

\section{ABSTRACT}

The purpose of this research are to analysis air quality and dust impact to people that came from factory activities at residential area around factory location of PT. Semen Padang. Measuring of air quality conducted in 3 residential area that are Komplek RW 1, RT 3 Batu Gadang district, Perumnas Indarung RW. VII, and housing of UNAND Blok D Gadut, using Personal Dust Sampler. The result is respirable dust concentration at housing complex RW. 1 RT. 3 Batu Gadang district that is $0,33 \mathrm{mg} / \mathrm{m}^{3}$, the Perumnas Indarung RW.VII that is $0,55 \mathrm{mg} / \mathrm{m}^{3}$ along with housing of UNAND Blok D Gadut that is $0,44 \mathrm{mg} / \mathrm{m}^{3}$. Concentration of dust respirable at all are still below ambient air quality standard that exist on PP RI No. 41 Tahun 1999, $3 \mathrm{mg} / \mathrm{m}^{3}$. Based on quesioner and puskesmas data proximate with use univariat analysis, negative impact who feels people are impact of health is eyes irritation disease and impact of environment especially community-owned material.

Keywords: air quality, negative impact, residential area, respirable dust, PT. Semen Padang

\section{PENDAHULUAN}

Debu respirable adalah partikel debu yang cukup kecil untuk menembus hidung dan sistem pernafasan bagian atas dan bagian dalam sampai ke paru-paru. Paparan yang berlebihan dari debu respirable yang berbahaya dapat mengakibatkan penyakit pernafasan yang disebut dengan pneumoconiosis. Penyakit ini disebabkan penggalian mineral atau partikel debu metalik pada paru-paru dan reaksi jaringan terhadap kasus tersebut (Noyes, 1990).
PT. Semen Padang merupakan salah satu perusahaan semen terbesar di Indonesia yang melakukan dua kegiatan, yaitu penambangan dan produksi semen. Produksi semen yang dilakukan PT. Semen Padang saat ini mencapai 6.000.000 ton/tahun yang dihasilkan dari empat pabrik yang ada. Produksi semen yang besar akan berdampak pada jumlah emisi yang dihasilkan. Besarnya jumlah material yang diemisikan dari kegiatan produksi akan berdampak negatif bagi lingkungan seperti hujan asam, gangguan pernafasan dan 
menambah kerak pada atap bangunan atau perumahan (Biro K3LH, 2013).

Pada tahun 2014, Yuliando (2014) melakukan pengukuran konsentrasi partikulat khususnya Total Suspended Particulate (TSP), di kawasan sekitar PT. Semen Padang. Hasil yang diperoleh berupa lokasi yang memiliki konsentrasi TSP yang tinggi sebesar 338,77 $\mu \mathrm{g} / \mathrm{Nm}^{3}$ selama 24 jam yaitu perumahan UNAND Blok D Gadut. Perumahan ini merupakan perumahan yang terletak di sekitar lokasi pabrik PT. Semen Padang. Konsentrasi tersebut berada di atas baku mutu udara ambien seperti yang terdapat pada PP RI No.41 Tahun 1999 tentang Pengendalian Pencemaran Udara, untuk parameter TSP dengan baku mutu sebesar $230 \mu \mathrm{g} / \mathrm{Nm}^{3}$, sehingga dengan tingginya konsentrasi TSP pada lokasi tersebut, dilakukanlah penelitian terhadap debu respirable yang terhirup oleh masyarakat serta dampak yang dirasakan masyarakat yang tinggal di kawasan perumahan sekitar lokasi pabrik PT. Semen Padang.

Dalam penelitian yang dilakukan sebelumnya, konsentrasi yang dihitung adalah konsentrasi TSP saja. TSP merupakan debu yang berada di lingkungan perumahan. Sementara yang kita ketahui bahwa partikulat yang memiliki dampak langsung terhadap masyarakat adalah $\mathrm{PM}_{10}, \quad \mathrm{PM}_{2,5}$, dan debu respirable (debu terhirup) yang dapat masuk ke dalam saluran pernafasan manusia. Untuk mengetahui debu yang terhirup oleh masyarakat yang tinggal di kawasan perumahan sekitar PT. Semen Padang, dilakukanlah penelitian menggunakan alat Personal Dust Sampler (PDS) untuk mendapatkan hasil berupa konsentrasi debu respirable. Penelitian menggunakan alat Personal Dust Sampler (PDS) belum pernah dilakukan sebelumnya jadi, penelitian ini merupakan penelitian pertama yang dilakukan di kawasan perumahan sekitar lokasi pabrik PT. Semen Padang dengan menggunakan alat Personal Dust Sampler (PDS).

Tuntutan dari masyarakat di kawasan perumahan sekitar PT. Semen Padang sudah banyak dilakukan kepada pihak PT. Semen Padang dan Pemerintah Daerah Kota Padang, tetapi tidak ada keputusan yang mendukung keluhan masyarakat. Tuntutan dilakukan lagi pada bulan Januari tahun 2014 oleh masyarakat
Perumnas Indarung yang sudah merasa tidak nyaman lagi tinggal di perumahan dekat lokasi pabrik PT. Semen Padang dan meminta ganti rugi kepada PT. Semen Padang, tetapi juga tidak ada keputusan yang mendukung masyarakat tersebut (Sekretaris Kecamatan Lubuk Kilangan, 2014). Dengan adanya kasus tersebut, penelitian ini perlu dilakukan untuk mengetahui seberapa besar debu respirable yang terhirup oleh masyarakat serta dampak yang dirasakan oleh masyarakat tersebut sehingga diharapkan dapat membantu permasalahan yang dialami masyarakat yang tinggal di kawasan perumahan sekitar lokasi pabrik PT. Semen Padang.

\section{METODOLOGI PENELITIAN}

Secara umum langkah-langkah pelaksanaan penelitian ini adalah survey pendahuluan, sampling, pengadaan kuisioner, dan dilanjutkan dengan analisis data.

\section{Survei Pendahuluan}

\section{a. Pengumpulan Data Sekunder}

Data sekunder yang diperlukan adalah data pendukung yang diperoleh dari instansi terkait. Adapun data-data yang diperlukan pada penelitian ini seperti data kesehatan masyarakat dari Puskesmas Kecamatan Lubuk Kilangan dan Puskesmas Pauh serta data kependudukan dari Kelurahan Padang Besi, Kelurahan Bandar Buat, Kelurahan Indarung dan Kelurahan Batu Gadang.

\section{b. Lokasi dan Waktu Sampling}

Lokasi sampling berjumlah 3 titik yang tersebar pada Kawasan Perumahan di sekitar lokasi pabrik PT. Semen Padang. Lokasi sampling ditetapkan berdasarkan pada daerah yang terkena dampak akibat aktivitas cerobong PT. Semen Padang yaitu Perumahan UNAND Blok D Gadut, daerah latar belakang atau referensi yaitu komplek perumahan RT. 3 RW.1 Kelurahan Batu Gadang serta daerah yang terletak di dekat lokasi packing plant PT. Semen Padang yaitu Perumnas Indarung RW. VII. Perkiraan sumber emisi partikulat di kawasan tersebut akibat kegiatan PT. Semen Padang sesuai dengan windrose atau arah angin dominan wilayah studi. Pemilihan lokasi ini dilihat bisa mewakili daerah daerah pemukiman 
atau tempat-tempat spesifik. Hal ini telah ditetapkan berdasarkan SNI 19-7119.6-2005 bagian 6 tentang penentuan lokasi pengambilan contoh uji pemantauan kualitas udara ambien. Untuk lebih jelasnya mengenai sketsa masingmasing lokasi sampling, dapat dilihat pada Gambar 1.

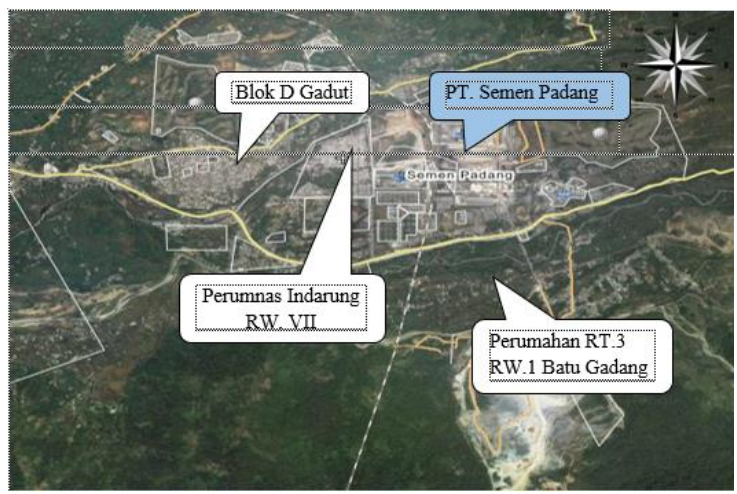

Gambar 1. Foto Udara Lokasi Sampling Sumber: Google Map, 2014

\section{c. Parameter Pengukuran}

Pada penelitian ini dilakukan pengukuran untuk menentukan konsentrasi debu respirable yaitu partikel debu terhirup berukuran $0,5 \mu \mathrm{m}$ sampai $4 \mu \mathrm{m}$.

\section{Sampling}

\section{a. Sampling Kondisi Meteorologi}

Data kondisi meteorologi yang diukur pada setiap lokasi sampling yaitu:

1. Temperatur $\left({ }^{\circ} \mathrm{C}\right)$, Tekanan udara $(\mathrm{mmHg})$ dan kelembaban relatif udara $(\mathrm{RH})$ dengan alat digital pocket weatherman;

2. Arah angin dengan kompas;

3. Kecepatan angin dengan alat anemometer;

4. Koordinat titik sampling dengan alat Global Positioning System (GPS).

\section{b. Sampling Debu Respirable}

Sampling dilakukan untuk pengambilan data primer, yang dilakukan selama 1 jam pada masing-masing titik pada siang dan malam hari. Sampling Debu Respirable menggunakan alat Personal Dust Sampler (PDS). PDS merupakan alat yang digunakan untuk mengukur konsentrasi debu dengan prinsip kerja menghisap udara dengan kecepatan 1,7 liter/menit melalui kertas filter sehingga udara yang melalui pipa akan tersaring oleh filter yang mempunyai berat tertentu. Pompa alat ini akan digantungkan pada pinggang responden dan inlet cyclone penampung debu digantungan pada bahu atau kerah baju responden, untuk mengetahui bentuk alat PDS, dapat dilihat pada Gambar 2.

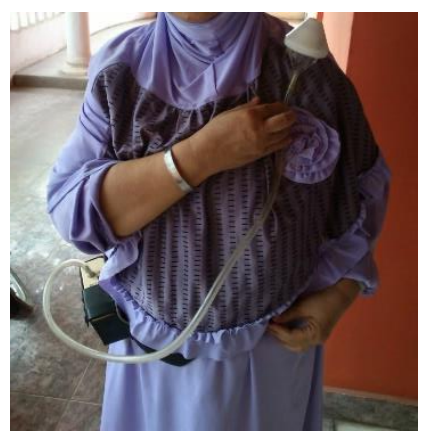

Gambar 2. Cara Pemakaian Alat Personal Dust Sampler (PDS)

\section{Pengambilan Data Kuesioner kepada Masyarakat}

Jumlah pengambilan data primer berupa data kuesioner kepada masyarakat ditentukan menggunakan persamaan minimal sampel size sehingga didapatkan jumlah sampel yang diperlukan dalam penelitian. Penentuan jumlah sampel untuk masing-masing kelurahan dilakukan berdasarkan seluruh jumlah KK di Perumnas Indarung, Perumahan UNAND Blok D Gadut, dan Perumahan dekat SMAN 14 Batu Gadang pada tahun 2014. Data kuesioner berisi tentang gambaran umum responden, riwayat penyakit, kebiasaan merokok, paparan terhadap rokok, paparan terhadap debu, dan keluhan masyarakat mengenai debu yang mencemari tempat tinggal masyarakat di kawasan sekitar lokasi pabrik PT. Semen Padang akibat aktivitas pabrik PT. Semen Padang. Dalam pemberian kuesioner akan dilakukan juga wawancara langsung dengan masyarakat tersebut.

\section{a. Populasi}

Populasi penelitian ini mencakup masyarakat yang tinggal di kawasan perumahan sekitar lokasi pabrik PT. Semen Padang, berikut rinciannya:

a. Perumnas Indarung $=378 \mathrm{KK}$

b. Perumahan UNAND Blok D Gadut $=1123$ KK

c. Perumahan dekat SMAN 14 Batu Gadang = $280 \mathrm{KK}$ 


\section{b. Sampel}

Penentuan jumlah sampel didasarkan pada data jumlah KK yang tinggal di kawasan perumahan sekitar lokasi pabrik PT. Semen Padang. Penentuan jumlah sampel dilakukan dengan menggunakan rumus minimal sampel size (Lemeshow dan David, 1997):

$$
\begin{aligned}
\mathrm{n} & =\frac{\mathrm{Z}^{2} . \mathrm{N} \cdot \mathrm{p} . \mathrm{q}}{\mathrm{d}^{2}(\mathrm{~N}-1)+\mathrm{Z} \cdot \mathrm{p} \cdot \mathrm{q}} \ldots \ldots \ldots \ldots \ldots \ldots \ldots \ldots \ldots \ldots \\
& =\frac{1,96^{2} \times 1781 \times 0.5 \times 0,5}{\left(0.1^{2} \times(1781-1)\right)+\left(1,96^{2} \times 0,5 \times 0,5\right)} \\
& =91,17 \approx 92 \mathrm{KK}
\end{aligned}
$$

Keterangan :

$\mathrm{n}$ = Besar sampel minimal

$\mathrm{N}=$ Jumlah populasi

$\mathrm{d}=$ Derajat ketepatan yang digunakan oleh

$90 \%$ atau 0,1

$\mathrm{p}=$ Proporsi target populasi adalah 0,5

$\mathrm{q}=$ Proporsi tanpa atribut $1-\mathrm{p}=0,5$

$\mathrm{Z}=$ Standar deviasi normal untuk 1,96 dengan CI $95 \%$

Jadi jumlah sampel dalam penelitian ini sebanyak 92 KK yang terdiri dari:

a. Perumnas Indarung $=(378 / 1781) 92=20 \mathrm{KK}$

b. Perumahan UNAND Blok D Gadut $=(1123 / 1781) 92=58 \mathrm{KK}$

c. Perumahan dekat SMAN 14 Padang $=(280 / 1781) 92=14 \mathrm{KK}$

Penentuan objek sampling dilakukan dengan memilih KK sebagai responden yang mewakili masyarakat yang berinteraksi langsung dengan lokasi sampling. Pengambilan sampel mengacu pada kriteria inklusi dan kriteria ekslusi sebagai berikut:

a. Kriteria inklusi

Kriteria inklusi merupakan kriteria dimana subjek penelitian mewakili sampel penelitian yang memenuhi syarat sebagai sampel (Ikhsan, 2013). Dalam penelitian ini yang menjadi kriteria inklusi adalah:
1. Masyarakat (KK) yang tinggal menetap di lokasi penelitian;
2. Laki-laki dan perempuan;
3. Bersedia menjadi responden.

b. Kriteria eksklusi

Kriteria eksklusi merupakan kriteria dimana subjek penelitian tidak dapat mewakili sampel karena tidak memenuhi syarat sebagai sampel penelitian, seperti adanya hambatan etis, menolak menjadi responden atau suatu keadaan yang tidak memungkinkan untuk dilakukan penelitian (Ikhsan, 2013). Kriteria eksklusi pada penelitian ini adalah:

1. Masyarakat (KK) yang sedang sakit;

2. Masyarakat (KK) yang tinggal menetap di lokasi penelitian, tetapi sedang tidak ada di lokasi penelitian;

3. Masyarakat (KK) yang menolak untuk menjadi responden.

\section{Analisis Data}

Analisis data meliputi analisis konsentrasi debu respirable dan analisis data kuisioner.

\section{a. Analisis Konsentrasi Debu Respirable}

Analisis konsentrasi debu respirable dilakukan dengan metode gravimetri yaitu menimbang berat debu yang tertahan di permukaan filter (selisih berat filter sesudah dan sebelum sampling). Filter blanko dan filter sampel ditimbang dengan menggunakan timbangan analitik yang sama sehingga diperoleh berat filter blanko dan filter sampel masing-masing $\mathrm{B}_{2}(\mathrm{mg})$ dan $\mathrm{W}_{2}(\mathrm{mg})$. Data hasil penimbangan berat filter tersebut diolah lebih lanjut untuk memperoleh konsentrasi debu respirable. Langkah-langkah perhitungan adalah sebagai berikut.

a. Hitung volume udara pada waktu pengambilan sampel

$$
\begin{aligned}
& \mathrm{V}=\mathrm{f} \times \mathrm{t} \\
& \text { Dimana: } \\
& \mathrm{V} \text { = volume udara pada waktu } \\
& \text { pengambilan sampel (liter) } \\
& \mathrm{f} \quad=\text { kecepatan aliran udara pada waktu } \\
& \text { pengambilan sampel (liter/menit) } \\
& \mathrm{t} \quad=\text { waktu pengambilan sampel (menit) }
\end{aligned}
$$

b. Hitung konsentrasi debu respirable $\left(\mathrm{mg} / \mathrm{m}^{3}\right)$

$$
\begin{aligned}
& \mathrm{C}=\frac{\left(\mathrm{W}_{2}-\mathrm{W}_{1}\right)-\left(\mathrm{B}_{2}-\mathrm{B}_{1}\right) \times 10^{3} \mathrm{mg} / \mathrm{m}}{\mathrm{V}} \ldots \ldots \ldots \ldots \ldots \ldots \ldots \ldots \ldots \ldots \ldots \ldots \ldots \ldots \ldots \ldots \ldots \ldots \ldots \ldots \ldots \ldots \\
& \ldots \ldots \ldots \ldots \ldots
\end{aligned}
$$




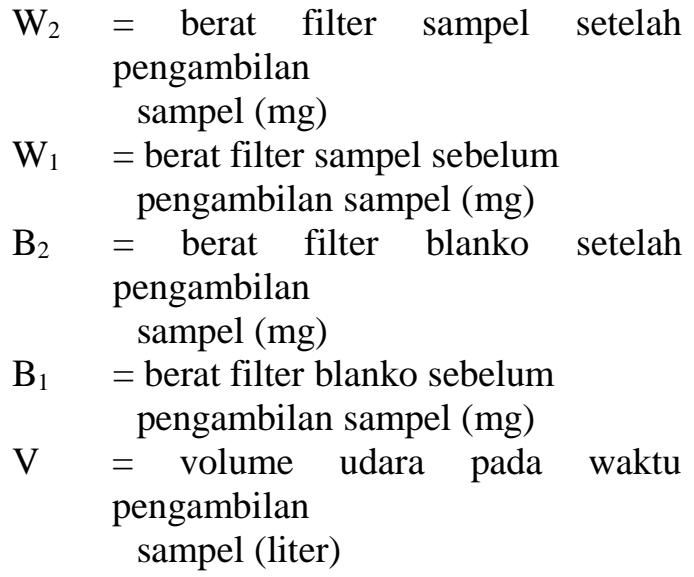

\section{b. Analisis Data Kuesioner}

Analisis yang digunakan adalah secara univariat. Data disajikan dalam bentuk tabel dan narasi. Langkah-langkah dalam menganalisis data kuesioner adalah sebagai berikut:

1. Pengolahan data

Pengolahan data dilakukan secara elektronik dengan software pengolah data SPSS versi 16, kemudian data yang telah diolah disajikan secara deskriptif dalam bentuk tabel dan narasi.

2. Analisis Data

Analisis data yang dilakukan tergantung pada tujuan penelitian, desain penelitian, serta skala pengukuran variabel yang digunakan. Model analisis data yang dilakukan adalah analisis univariat yaitu hasil penelitian akan dideskripsikan dengan menggunakan tabel distribusi frekuensi dan analisis presentasi (Ikhsan, 2013). Analisis data dilakukan setelah data diolah dalam program komputerisasi. Analisis dalam penelitian ini dilakukan secara deskriptif.

Analisis univariat.

Analisis univariat hanya terbatas pada analisis deskriptif untuk setiap varibel pada sampel. Tujuan analisis ini adalah untuk mengetahui karakteristik setiap variabel pada sampel (Ikhsan, 2013). Dalam uji korelasi Pearson Product Moment digunakan asumsi sebelum menghitung koefisien korelasi parsial, asumsinya dapat dijabarkan sebagai berikut (Usman dan Akbar, 2000):

1) Data berdistribusi normal;

2) Variabel yang dihubungkan mempunyai data yang linear;
3) Variabel yang dihubungkan mempunyai data yang dipilih secara acak;

4) Variabel yang dihubungkan mempunyai pasangan yang sama dari subyek yang sama pula (variasi skor variabel yang dihubungkan harus sama);

5) Variabel yang dihubungkan mempunyai data interval atau rasio.

Setelah penentuan asumsi telah dilakukan, selanjutnya kita melakukan perhitungan koefisien korelasi parsial. Mencari $\mathrm{r}_{\text {hitung }}$ menggunakan rumus sebagai berikut:

$$
r_{x y}=\frac{n \sum X Y-\sum X \cdot \sum Y}{\sqrt{n \sum X^{2}-\left(\sum X\right)^{2}} \sqrt{n \sum Y^{2}-\left(\sum Y\right)^{2}}} .
$$

Mencari besarnya sumbangan (kontribusi) variabel $\mathrm{X}$ terhadap $\mathrm{Y}$ dengan rumus yaitu:

$$
\mathrm{KP}=\mathrm{r}^{2} \times 100 \%
$$

\section{HASIL DAN PEMBAHASAN}

Bagian ini menjelaskan data-data hasil pengukuran di wilayah studi, hasil analisis, dan pembahasannya. Pembahasan tersebut meliputi analisis meteorologi serta analisis hasil konsentrasi debu respirable. Selain itu, dilanjutkan dengan pembahasan hasil analisis kuesioner secara univariat dengan menggunakan program SPSS dan uji korelasi Pearson Product Moment serta data pendukung dari Puskesmas Kecamatan Lubuk Kilangan untuk menentukan dampak negatif yang dirasakan masyarakat di wilayah perumahan sekitar lokasi pabrik PT. Semen Padang.

\section{Kondisi Meteorologi}

Kondisi meteorologi adalah salah satu faktor yang mempengaruhi pengukuran kualitas udara ambien. Kondisi meteorologi sangat mempengaruhi besarnya nilai konsentrasi partikulat di lokasi pengukuran. Kondisi meteorologi yang diukur terdiri dari arah dan kecepatan angin $(\mathrm{m} / \mathrm{s})$, kelembaban relatif udara $(\%)$, suhu udara $\left({ }^{\circ} \mathrm{C}\right)$, dan tekanan udara $(\mathrm{mmHg})$. Berikut rekapitulasi kondisi meteorologi pada saat pengukuran selama 24 jam di wilayah studi dapat dilihat pada Tabel 1 . 


\section{Konsentrasi Debu Respirable}

Debu respirable yang diukur adalah debu yang terhirup oleh responden selama beraktivitas dalam satu hari. Responden yang menjadi sampel dalam pengukuran adalah ibu rumah tangga yang rumahnya terletak di wilayah studi penelitian ini. Debu respirable diukur selama 1 jam pada siang hari dan 1 jam pada malam hari. Berikut konsentrasi debu respirable di wilayah studi selama 1 jam pada siang dan malam hari dapat dilihat pada Tabel 2.

Berdasarkan Tabel 2 dapat dilihat konsentrasi debu respirable pada siang hari dan malam hari pada masing-masing perumahan pada saat sampling selama 1 jam relatif sama. Kemudian konsentrasi selama 1 jam tersebut dikonversikan dengan menggunakan persamaan konversi canter untuk mendapatkan konsentrasi debu respirable yang mewakili siang dan malam hari selama 12 jam serta mendapatkan konsentrasi debu respirable selama 24 jam. Konsentrasi debu respirable di kawasan perumahan sekitar lokasi pabrik PT.Semen Padang dapat dilihat pada Tabel 3.

Konsentrasi debu respirable yang diperoleh pada lokasi penelitian dibandingkan dengan Permenakertrans No. 13/MEN/X/2011 tentang Nilai Ambang Batas Faktor Fisika dan Faktor Kimia di Tempat Kerja untuk partikel respirable karena berdasarkan peraturan tersebut karakteristik perumahan di kawasan sekitar lokasi pabrik PT. Semen Padang mirip dengan pengertian tempat kerja yang tercantum pada Permenakertrans No. 13/MEN/X/2011 yakni setiap ruangan atau lapangan yang tertutup atau terbuka, bergerak atau tetap, di mana tenaga kerja bekerja atau sering dimasuki tenaga kerja untuk keperluan suatu usaha dan di mana terdapat sumber-sumber bahaya. Karakteristik perumahan di kawasan sekitar lokasi pabrik PT. Semen Padang yaitu berupa ruangan tertutup (dalam rumah) dan lapangan terbuka (luar rumah) di mana masyarakat yang tinggal di kawasan perumahan adalah manusia yang sama karakteristiknya dengan tenaga kerja
Tabel 1. Rekapitulasi Kondisi Meteorologi Saat Pengukuran di Wilayah Studi

\begin{tabular}{|c|c|c|c|c|c|c|c|}
\hline \multirow[b]{2}{*}{$\begin{array}{l}\mathbf{N} \\
\mathbf{0}\end{array}$} & \multirow[b]{2}{*}{$\begin{array}{c}\text { Lokasi } \\
\text { Sampling }\end{array}$} & \multirow[b]{2}{*}{$\begin{array}{c}\text { Waktu } \\
\text { Sampli } \\
\text { ng }\end{array}$} & \multicolumn{5}{|c|}{ Parameter Meteorologi } \\
\hline & & & $\begin{array}{l}\text { Su } \\
\text { hu } \\
\left({ }^{\circ}\right. \\
\text { C) }\end{array}$ & $\begin{array}{c}\mathbf{R} \\
\mathbf{H} \\
( \\
\% \\
)\end{array}$ & $\begin{array}{c}\text { Tekan } \\
\text { an } \\
(\mathbf{m m H} \\
\mathbf{g})\end{array}$ & $\begin{array}{c}\text { Ke } \\
\text { c. } \\
\text { An } \\
\text { gin } \\
(\mathbf{m} / \\
\text { s) }\end{array}$ & $\begin{array}{c}\text { Arah Angin } \\
\text { Dominan }\end{array}$ \\
\hline 1 & $\begin{array}{l}\text { Komp } \\
\text { lek } \\
\text { perum } \\
\text { ahan } \\
\text { RT.3 } \\
\text { RW.1 } \\
\text { Kelura } \\
\text { han } \\
\text { Batu } \\
\text { Gadan } \\
\text { g }\end{array}$ & $\begin{array}{c}\text { Kam } \\
\text { is, } \\
1 \\
\text { Mei } \\
2014\end{array}$ & $\begin{array}{c}2 \\
8, \\
3 \\
6\end{array}$ & $\begin{array}{c}9 \\
8 \\
7 \\
2\end{array}$ & $\begin{array}{r}741, \\
45\end{array}$ & $\begin{array}{r}0, \\
5 \\
3\end{array}$ & $\begin{array}{r}\text { Calm } \\
(15 \%) \\
\text { Selatan } \\
(5 \%) \\
\text { Barat } \\
\text { Daya (3 } \\
\%) \\
\text { Tenggar } \\
\text { a (7 \%) } \\
\text { Timur } \\
(24 \%) \\
\text { Timur } \\
\text { Laut (6 } \\
\%) \\
\text { Barat } \\
\text { (40 \%) }\end{array}$ \\
\hline 2 & $\begin{array}{l}\text { Perum } \\
\text { nas } \\
\text { Indaru } \\
\text { ng } \\
\text { RW.V } \\
\text { II }\end{array}$ & $\begin{array}{c}\text { Jum } \\
\text { at, } \\
2 \\
\text { Mei } \\
2014\end{array}$ & $\begin{array}{c}2 \\
8, \\
9 \\
2\end{array}$ & $\begin{array}{c}9 \\
9, \\
4 \\
1\end{array}$ & $\begin{array}{r}743, \\
79\end{array}$ & $\begin{array}{r}0, \\
3 \\
6\end{array}$ & $\begin{array}{r}\text { Calm } \\
(22 \%) \\
\text { Barat } \\
\text { Laut (14 } \\
\%) \\
\text { Barat } \\
\text { Daya (7 } \\
\%) \\
\text { Tenggar } \\
\text { a }(2 \%) \\
\text { Timur } \\
\text { Laut (3 } \\
\%) \\
\text { Selatan } \\
(5 \%) \\
\text { Utara (1 } \\
\%) \\
\text { Barat } \\
(21 \%) \\
\text { Timur } \\
(\mathbf{2 5} \%) \\
\end{array}$ \\
\hline 3 & $\begin{array}{l}\text { Perum } \\
\text { ahan } \\
\text { UNA } \\
\text { ND } \\
\text { Blok } \\
\text { D } \\
\text { Gadut }\end{array}$ & $\begin{array}{c}\text { Sabt } \\
\text { u, } \\
3 \\
\text { Mei } \\
2014\end{array}$ & $\begin{array}{c}2 \\
7 \\
9 \\
4\end{array}$ & $\begin{array}{c}9 \\
8, \\
1 \\
2\end{array}$ & $\begin{array}{r}744 \\
54\end{array}$ & $\begin{array}{r}0, \\
6\end{array}$ & $\begin{array}{r}\text { Calm } \\
(30 \%) \\
\text { Barat } \\
\text { Laut }(7 \\
\%) \\
\text { Timur } \\
\text { Laut (8 } \\
\%) \\
\text { Utara (3 } \\
\%) \\
\text { Tenggar } \\
\text { a (2\%) } \\
\text { Barat } \\
(16 \%) \\
\text { Timur } \\
(33 \%)\end{array}$ \\
\hline
\end{tabular}


Tabel 2. Konsentrasi Debu Respirable Pada Kawasan Perumahan Sekitar Lokasi Pabrik PT. Semen Padang Pada Siang dan Malam Hari Selama 1 Jam

\begin{tabular}{|c|c|c|c|c|}
\hline \multirow{2}{*}{ No. } & \multirow{2}{*}{$\begin{array}{c}\text { Lokasi } \\
\text { Sampling }\end{array}$} & \multirow{2}{*}{$\begin{array}{c}\text { Waktu } \\
\text { Samplin } \\
\text { g }\end{array}$} & \multicolumn{2}{|c|}{$\begin{array}{l}\text { Konsentrasi Debu } \\
\text { Respirable }\left(\mathrm{mg} / \mathrm{m}^{3}\right)\end{array}$} \\
\hline & & & Siang & Malam \\
\hline 1 & $\begin{array}{l}\text { Komplek } \\
\text { perumah } \\
\text { an RT.3 } \\
\text { RW.1 } \\
\text { Keluraha } \\
\text { n Batu } \\
\text { Gadang }\end{array}$ & $\begin{array}{c}\text { Kamis, } \\
1 \text { Mei } \\
2014\end{array}$ & 0,59 & 0,59 \\
\hline 2 & $\begin{array}{l}\text { Perumna } \\
\text { s } \\
\text { Indarung } \\
\text { RW.VII }\end{array}$ & $\begin{array}{c}\text { Jumat, } \\
2 \text { Mei } \\
2014\end{array}$ & 0,98 & 0,98 \\
\hline 3 & $\begin{array}{l}\text { Perumah } \\
\text { an } \\
\text { UNAND } \\
\text { Blok D } \\
\text { Gadut }\end{array}$ & $\begin{array}{l}\text { Sabtu, } \\
3 \text { Mei } \\
2014\end{array}$ & 0,78 & 0,78 \\
\hline
\end{tabular}

Tabel 3. Konsentrasi Debu Respirable Pada Kawasan Perumahan Sekitar Lokasi Pabrik PT. Semen Padang

\begin{tabular}{|c|c|c|c|c|c|}
\hline \multirow[t]{2}{*}{$\begin{array}{l}\text { 1 } \\
\text { o } \\
\text {. }\end{array}$} & \multirow[t]{2}{*}{$\begin{array}{c}\text { Lokasi } \\
\text { Sampling }\end{array}$} & \multirow{2}{*}{$\begin{array}{l}\text { Wak } \\
\text { tu } \\
\text { Sam } \\
\text { pling }\end{array}$} & \multicolumn{2}{|c|}{$\begin{array}{l}\text { Konsentr } \\
\text { asi Debu } \\
\text { Respirabl } \\
e\left(\mathrm{mg}^{2} \mathbf{m}^{3}\right)\end{array}$} & \multirow{2}{*}{$\begin{array}{l}\text { Kons } \\
\text { entra } \\
\text { si } 24 \\
\text { Jam } \\
(\mathrm{mg} / \\
\left.\mathrm{m}^{3}\right) \\
\end{array}$} \\
\hline & & & $\begin{array}{c}\text { Sia } \\
\text { ng }\end{array}$ & $\begin{array}{c}\text { Mal } \\
\text { am }\end{array}$ & \\
\hline 1 & $\begin{array}{l}\text { Komplek } \\
\text { perumaha } \\
\text { n RT.3 } \\
\text { RW.1 } \\
\text { Kelurahan } \\
\text { Batu } \\
\text { Gadang }\end{array}$ & $\begin{array}{c}\text { Kam } \\
\text { is, } \\
1 \\
\text { Mei } \\
2014\end{array}$ & $\begin{array}{r}0,3 \\
9\end{array}$ & $\begin{array}{r}0,3 \\
9\end{array}$ & 0,33 \\
\hline 2 & $\begin{array}{l}\text { Perumnas } \\
\text { Indarung } \\
\text { RW.VII }\end{array}$ & $\begin{array}{c}\text { Juma } \\
\text { t, } \\
2 \\
\text { Mei } \\
2014 \\
\end{array}$ & $\begin{array}{r}0,6 \\
4\end{array}$ & $\begin{array}{r}0,6 \\
4\end{array}$ & 0,55 \\
\hline 3 & $\begin{array}{l}\text { Perumaha } \\
\mathrm{n} \\
\text { UNAND } \\
\text { Blok D } \\
\text { Gadut }\end{array}$ & $\begin{array}{c}\text { Sabt } \\
\text { u, } \\
3 \\
\text { Mei } \\
2014 \\
\end{array}$ & $\begin{array}{r}0,5 \\
1\end{array}$ & $\begin{array}{r}0,5 \\
1\end{array}$ & 0,44 \\
\hline
\end{tabular}

kerja yang juga manusia, jadi dapat dikatakan Permenakertrans No. 13/MEN/X/2011 tentang Nilai Ambang Batas Faktor Fisika dan Faktor Kimia di Tempat Kerja dapat dibandingkan dengan debu respirable yang diperoleh pada kawasan perumahan sekitar lokasi pabrik PT. Semen Padang.

Konsentrasi yang diperoleh di lokasi penelitian menunjukkan masih rendahnya konsentrasi debu respirable pada kawasan perumahan sekitar lokasi pabrik PT. Semen Padang jika dibandingkan dengan Nilai Ambang Batas Faktor Fisika dan Faktor Kimia di Tempat Kerja untuk debu respirable sebesar $3 \mathrm{mg} / \mathrm{m}^{3}$. Rendahnya konsentrasi debu respirable disebabkan aktivitas responden yang merupakan ibu rumah tangga yang tinggal di kawasan perumahan sekitar lokasi pabrik PT. Semen Padang lebih banyak dilakukan di dalam rumah sehingga kemungkinan paparan terhadap debu respirable menjadi kecil.

\section{Dampak Negatif yang Dirasakan Masyarakat di Kawasan Perumahan Sekitar Lokasi Pabrik PT. Semen Padang}

Penentuan dampak negatif yang dirasakan masyarakat di kawasan perumahan sekitar lokasi pabrik PT. Semen Padang dilakukan dengan cara mengolah data-data kuesioner yang diperoleh di masing-masing wilayah studi yaitu pada komplek perumahan RT.3 RW.1 Kelurahan Batu Gadang, Perumnas Indarung RW.VII dan Perumahan UNAND Blok D Gadut ke dalam program SPSS versi 16 kemudian dilakukan analisis data secara univariat. Hasilnya akan disesuaikan dengan data pendukung dari Puskesmas Kecamatan Lubuk Kilangan dan dari Puskesmas Kecamatan Pauh.

\section{Analisis Univariat}

Jumlah sampel dalam penelitian ini adalah 92 KK di kawasan perumahan sekitar lokasi pabrik PT. Semen Padang dengan pembagian $20 \mathrm{KK}$ di Perumnas Indarung RW. VII, 58 KK di Perumahan UNAND Blok D Gadut, dan 14 KK di komplek perumahan RT.3 RW.1 Kelurahan Batu Gadang. Analisis univariat yang dibahas pada penelitian ini adalah sebagai berikut:

1. Distribusi pengaruh debu terhadap kesehatan responden;

2. Distribusi pengaruh debu terhadap material responden. 
Adapun paparan terhadap kesehatan masyarakat yang tinggal di kawasan perumahan sekitar lokasi pabrik PT. Semen Padang jika dilihat dari analisis univariat antara lain dapat mengakibatkan penyakit iritasi mata, batuk, flu, sesak nafas, dan alergi. Hal ini didukung juga dengan data dari Puskesmas Kecamatan Lubuk Kilangan bahwa untuk kategori 10 penyakit terbanyak pada kawasan perumahan sekitar lokasi pabrik PT. Semen Padang pada bulan Mei tahun 2014 yang waktunya sama dengan saat dilakukannya pengukuran kualitas udara untuk parameter TSP adalah penyakit ISPA. Batuk, flu, alergi dan sesak nafas tergolong kepada penyakit ISPA.

Data 10 penyakit terbanyak juga diambil dari Puskesmas Kecamatan Pauh yang daerahnya tidak terpapar oleh debu dari aktivitas pabrik PT. Semen Padang (sebagai pembanding) pada bulan Mei tahun 2014 juga diperoleh ISPA merupakan penyakit terbanyak pada bulan tersebut. Jika data 10 penyakit terbanyak dari Puskesmas Kecamatan Lubuk Kilangan tersebut dibandingkan dengan data dari Puskesmas Kecamatan Pauh, maka dapat disimpulkan pada bulan Mei tahun 2014 memang penyakit ISPA yang sering terjadi. Hal ini berarti bahwa penyebab penyakit ISPA yang dialami masyarakat yang tinggal di kawasan sekitar lokasi pabrik PT. Semen Padang tidak hanya berasal dari pengaruh debu pabrik PT. Semen Padang saja tetapi, juga disebabkan oleh aspek lingkungan yang lainnya seperti suhu udara yang tidak stabil (musim pancaroba) dan disebabkan oleh virus.

Sedangkan, untuk keluhan penyakit iritasi mata yang tidak termasuk penyakit ISPA dapat dikatakan dipengaruhi oleh debu yang berasal dari aktivitas pabrik PT. Semen Padang. Hal ini dibuktikan dengan data respondensi masyarakat Perumnas Indarung RW. VII mayoritas memilih keluhan penyakit iritasi mata akibat debu yang berasal dari aktivitas pabrik PT. Semen Padang. Data tersebut sesuai dengan referensi yang menyebutkan bahwa debu semen memiliki efek iritasi pada kulit, mata dan sistem pernapasan (Meo, 2003), sehingga mengakibatkan masyarakat yang tinggal di Perumnas Indarung RW. VII merasakan keluhan kesehatan iritasi mata ketika tinggal di perumahan tersebut.
Pengaruh debu terhadap material di kawasan perumahan sekitar lokasi pabrik PT. Semen Padang berdasarkan data respondensi antara lain dapat mengakibatkan atap rumah yang bocor, lantai dan kaca rumah sulit dibersihkan, tanaman yang rusak bahkan mati, jalanan licin karena dipenuhi debu, pagar rumah dan talang hujan yang cepat rusak, kendaraan yang diparkir di luar yang lengket dengan debu, perabotan rumah tangga cepat rusak, cat rumah yang cepat pudar, kain yang dijemur di luar rumah timbul bintik2 hitam, dan saluran drainase atau got yang mengeras akibat debu sehingga tersumbat. Hal ini disesuaikan dengan referensi yang menyebutkan bahwa debu yang dihasilkan industri semen dapat berpengaruh terhadap lingkungan dan manusia (Khairiah dkk, 2012) jadi, dapat disimpulkan bahwa debu dari aktivitas pabrik PT. Semen Padang berpengaruh terhadap lingkungan khususnya pada kondisi material yang dimiliki oleh masyarakat.

\section{PENUTUP}

\section{Kesimpulan}

Berdasarkan penelitian yang telah dilakukan di kawasan perumahan sekitar lokasi pabrik PT. Semen Padang dapat disimpulkan hal-hal sebagai berikut:

1. Konsentrasi debu respirable pada komplek perumahan RT.3 RW.1 Kelurahan Batu Gadang sebesar $0,33 \mathrm{mg} / \mathrm{m}^{3}$, pada Perumnas Indarung RW.VII sebesar $0,55 \mathrm{mg} / \mathrm{m}^{3}$ serta pada Perumahan UNAND Blok D Gadut sebesar $0,44 \mathrm{mg} / \mathrm{m}^{3}$.

2. Dampak yang dirasakan masyarakat di kawasan sekitar lokasi pabrik PT. Semen Padang akibat aktivitas pabrik PT. Semen Padang berdasarkan analisis univariat adalah dampak terhadap kesehatan berupa keluhan penyakit iritasi mata dan dampak terhadap lingkungan khususnya pada kondisi material yang dimiliki oleh masyarakat.

\section{Saran}

Adapun saran yang dapat diberikan dalam penelitian ini adalah:

1. Perlu dilakukan pengukuran debu respirable (debu terhirup) selama 24 jam pada masyarakat agar hasil konsentrasi yang didapatkan lebih representatif; 
2. Bagi pemerintah untuk dapat membuat peraturan mengenai baku mutu udara untuk debu respirable di lingkungan pemukiman atau perumahan;

3. Perlu dilakukan pengendalian oleh pihak PT. Semen Padang pada area Packing Plant dan pada sistem transportasi pengangkutan semen. Pada area Packing Plant dapat dilakukan pengendalian dengan mengganti proses pengemasan semen yang sebagian dilakukan secara manual dengan proses yang dilakukan secara otomatis seluruhnya (dengan menggunakan alat bantu) sehingga dapat mengurangi kadar debu yang berterbangan sekaligus memudahkan pekerjaan pengemasan semen agar lebih singkat dan efisien. Sedangkan, untuk transportasi semen yang melewati kawasan Perumnas Indarung RW. VII diharapkan dapat menutup semen yang akan diangkut atau menggunakan truk yang ada penutupnya sehingga kemungkinan jatuhnya debu dari truk menjadi kecil;

4. Bagi masyarakat yang tinggal di Perumnas Indarung RW.VII dapat menanam pohon mahoni atau pohon tanjung karena pohon tersebut mampu menyerap (mengurangi jatuhnya) debu semen.

\section{DAFTAR PUSTAKA}

Biro K3LH. 2013. Nuansa Pagi Bulan Agustus 2013. Padang: PT Semen Padang

Google Map 2014.

Ikhsan. 2013. Analisis Daya Ingat Lansia di Unit Rehabilitasi Sosial Dewanata Cilacap. Bandung: Skripsi Universitas Padjajaran

Khairiah, Ashar, T. dan Santi, D.N. 2012. Analisis Konsentrasi Debu dan Keluhan Kesehatan Pada Masyarakat di Sekitar Pabrik Semen di Desa Kuala Indah Kecamatan Sei Suka Kabupaten Batu Bara tahun 2012. Medan: USU Press

Lemeshow,S dan David W.H.Jr. 1997. Besar Sampel dalam Penelitian Kesehatan (Terjemahan). Yogyakarta: Gajahmada University Press

Menteri Tenaga Kerja dan Transmigrasi Republik Indonesia. 2011. Peraturan Menteri Tenaga Kerja dan Transmigrasi Nomor Per. 13/MEN/X/2011 tentang
Nilai Ambang Batas Faktor Fisika dan Faktor Kimia di Tempat Kerja. Jakarta

Meo, S.A. 2003. Chest Radiological Findings in Pakistani Cement Factory Workers. Saudi Medical Journal Vol. (3): 287-290. http://www.smj.org.sa/DetailArticle.asp \%3FArticleId\%3D1198. Tanggal Akses: 18 Juli 2012

Noyes, R. 1990. Handbook of Polution Control Processes. United States of America: Noyes Publications

Pemerintah Republik Indonesia. 1999. Peraturan Pemerintah Republik Indonesia No. 41 Tahun 1999 tentang Pengendalian Pencemaran Udara. Sekretaris Kabinet Republik Indonesia. Jakarta

Sekretaris Kecamatan Lubuk Kilangan. 2014. Wawancara "Tuntutan Masyarakat Perumnas Indarung terhadap Debu yang Berasal dari Aktivitas Pabrik PT. Semen Padang" di Kantor Kecamatan Lubuk Kilangan, Kota Padang

SNI 19-0232-2005. 2005. Nilai Ambang Batas (NAB) Zat Kimia di Udara Tempat Kerja. Indonesia: BSN

SNI 19-7119.6-2005. 2005. Udara Ambien Bagian 6: Penentuan Lokasi pengambilan Contoh Uji Pemantauan Kualitas Udara Ambien. Indonesia: BSN Usman dan Akbar. 2000. Pengantar Statistika. Jakarta: Bumi Aksara

Yuliando, D.T. 2014. Pemetaan Konsentrasi Total Suspended Particulate (TSP) dan Konsentrasi Logam Ca, Si, Al, Fe, Na di Udara Ambien Kawasan Barat PT. Semen Padang dan Sekitarnya. Padang: Tugas Akhir Teknik Lingkungan Universitas Andalas. 